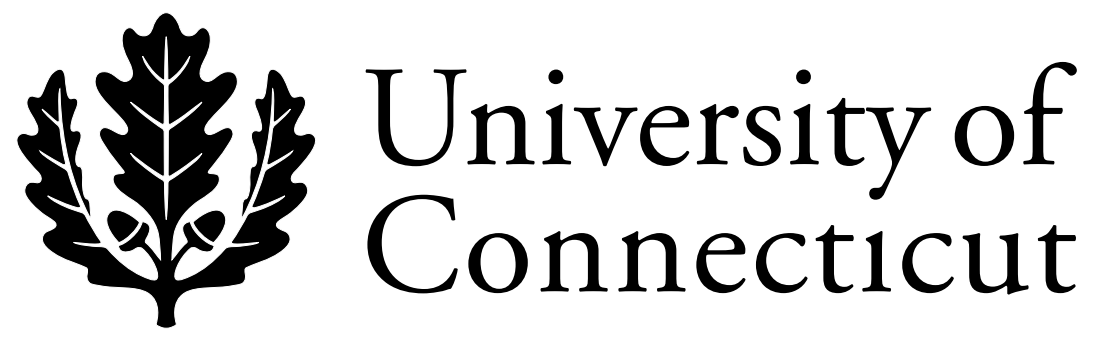

Department of Economics Working Paper Series

Economic Growth, Longevity, and the Epidemiological Transition

Olivier F. Morand

University of Connecticut

Working Paper 2002-07

July 2002

341 Mansfield Road, Unit 1063

Storrs, CT 06269-1063

Phone: (860) 486-3022

Fax: (860) 486-4463

http://www.econ.uconn.edu/ 


\begin{abstract}
This paper integrates investments in health to a standard growth model where physical and human capital investments are the combined engines of growth. It shows the existence of two distinct health regimes separated by an 'Epidemiological Transition'. The various patterns of the transition identified in the epidemiological literature can be mapped into the model. The model also leads to the important hypothesis that the epidemiological transition may induce an economy to switch to a modern growth regime.
\end{abstract}

Journal of Economic Literature Classification: O0, I0, D9

Keywords: growth, longevity 


\title{
Economic Growth, Longevity, and the Epidemiological Transition
}

\author{
Olivier F. Morand \\ Department of Economics \\ University of Connecticut \\ Storrs, CT 06269 \\ July 2002 \\ Keyword: Growth, Longevity \\ JEL Codes: O0, I0, D9
}

\begin{abstract}
This paper integrates investments in health to a standard growth model where physical and human capital investments are the combined engines of growth. It shows the existence of two distinct health regimes separated by an "Epidemiological Transition." The various patterns of this transition identified in the epidemiological literature can be mapped into the model. The model also leads to the important hypothesis that the epidemiological transition may induce an economy to switch to a modern growth regime.
\end{abstract}

\section{Introduction}

The strong correlations between various measures of health and income per capita have led macroeconomists to regard health as an essential part of any measure of well-being, ${ }^{1}$ although better health and longer life expectancy are mostly viewed as by-products of the economic growth and development of a country. In contrast, microeconomists looked carefully at the determinants of the demand for health and established that the relationship between health and income runs both ways: Health is analogous to a normal good, and higher income leads to an increased demand for health, but the health status of a person also affects his or her income and earnings through different channels (Grossman 1972). These important results are forcing economists to rethink their analysis of the relationship between economic growth, health and longevity in the light of macroeconomic growth models that integrate the microfoundations of health

\footnotetext{
${ }^{1}$ Life expectancy is included in the Human Development Index.
} 
economics. $^{2}$ This paper follows that goal and develops a theoretical framework that better explains the historical relationship between income and a particular measure of health, longevity, by integrating results from the field of health economics into an endogenous growth model.

The paper provides a setting for explaining important empirical findings stemming from a broad literature in various fields. First, paleodemographic studies have established that life expectancy at birth hardly increased between the time of prehistoric hunter-gatherers and the end of the 18th Century (Acsadi and Nemeskeri 1970, Hassan 1981), despite a change in the mode of production -the agricultural revolution- and a slow but irregular rise in income per capita over time (Kremer 1993, Morand 2000). Second, demographers and economists have documented the tremendous gains in longevity and income characterizing the period from the 19th Century to the present in many countries. Third, the clear differences in the main causes of mortality between these two periods has led epidemiologists to use the term of "Epidemiological Transition" to refer to the dramatic changes between the two periods; it is a transition that seems to parallel the demographic and technological transition in the developed economies, and which occurred more recently in less-developed economies (Omran 1971, 1982, Haines 1995). Finally, different patterns, paces, and dynamics for the complex interaction between mortality and economic growth (and, more generally, between demographic and economic variables) during this transition have been identified and gathered under the name "Theory of the Epidemiological Transition" (Omran 1971, 1982). This paper presents a theory that unifies these distinctive patterns of the Epidemiological Transition, and also generates new hypothesis concerning the interaction between health and long-term economic growth.

The framework developed below combines recent developments in the endogenous growth literature (Galor and Moav 2000, Galor and Weil 1999, 2000, Lucas 1998) to the seminal work of Grossman (1972) in health economics. Specifically, in an endogenous growth model where output is produced by combining physical and human capital, agents can also invest in health and therefore increase their health status or stock, which in turn positively affects their utility. Consequently, economic growth has a direct effect on health status and longevity, providing that health is a normal good. However, a change in life expectancy can in turn affect growth through its effect on agents' capital investment, a mechanism emphasized in the literature on savings under uncertainty (see, for instance, Mirman 1971). Thus, a channel exists through which health status and longevity of a population may affect the economic growth.

The paper is organized as follows. Consistent with the standard findings of the endogenous growth literature, Section 2 shows that a neoclassical regime during which growth is fueled exclusively by the accumulation of physical capital is followed by a modern regime in which both types of capitals contribute to

\footnotetext{
${ }^{2}$ One notable contribution is that of Van Zon and Muysken (2001) who introduce a health sector in an endogenous growth model to examine the tradeoff between health and human capital accumulation. Bloom and Canning (2000) informally discuss the various mechanisms connecting growth and health.
} 
growth. Section 3 demonstrates that an epidemiological transition to a regime of increasing longevity can be triggered by an income threshold during either one of the two regimes, or, alternatively, by an exogenous change in some of the parameters of the model. These three different theoretical scenarios are shown to match very closely to the three generic patterns of the epidemiological transition observed by epidemiologists. The paper also raises the important hypothesis that an epidemiological transition can accelerate, and perhaps even induce, the switch between the neoclassical regime and the modern regime. Section 4 concludes.

\section{The Basic Growth Setup}

Consider a simple model with overlapping generations of identical agents living for two periods, called young age and maturity, and suppose that cohorts are of constant (large) size $N$. An agent born in period $t$ has preferences over the consumption of a single good in each period of his life, respectively denoted $c_{t}^{y}$ and $c_{t+1}^{m}$, which are represented by the following utility function:

$$
u\left(c_{t}^{y}\right)+u\left(c_{t+1}^{m}\right),
$$

where the period utility $u$ is $C^{2}$, strictly increasing and strictly concave. The superscript indicates which cohort the agent belongs to (young vs. mature), the subscript, the particular period considered, and the function $u(c)=\ln (c)$ will be used in the paper when closed form solutions better illustrate the results.

Following the standard endogenous growth literature (see for instance, Galor and Moav 2000, Galor and Weil 1999, 2000), the consumption good in each period is produced by a firm using a constant return to scale technology in aggregate physical capital $K_{t}$ and human capital $H_{t}$ according to the production function:

$$
Y_{t}=A K_{t}^{\alpha} H_{t}^{1-\alpha}=A k_{t}^{\alpha} H_{t} \text { with } k_{t}=K_{t} / H_{t} \text { and } 0<\alpha<1 .
$$

The quantity $k_{t}$ is thus the capital stock per unit of human capital during period $t$. The firm is perfectly competitive in the output and inputs markets, so it does not matter who owns the firm since the factor payments completely exhaust the revenues from selling the output. ${ }^{3}$ Consequently, the interest rate and the wage rate per unit of labor are, respectively:

$$
w_{t}=A(1-\alpha) k_{t}^{\alpha} \text { and } r_{t}=A \alpha k_{t}^{\alpha-1} .
$$

Finally, young agents in period $t$ are endowed with a basic human capital level denoted $h_{t}^{y}$. Human capital has two important characteristics. First, the young generation can increase its stock of human capital by making costly investments, as in the seminal work of Lucas (1988). Specifically, if $e_{t}$ denotes

\footnotetext{
${ }^{3}$ To simplify, it is assumed that all capital fully depreciates when used in the process of production.
} 
the resources invested in human capital accumulation/production in period $t$ by a young agent, then:

$$
h_{t+1}^{m}=h_{t}^{y} \mu\left(e_{t}\right),
$$

where $\mu$ is smooth, strictly increasing and concave, $\mu(0)=1$, and $\mu^{\prime}(0)=\gamma<$ $\infty$.

The second characteristic of human capital stems from the property that some of the existing body of knowledge and skills does not have to be entirely rediscovered by the new generation, but is communicated or transmitted from one generation to the next at no cost. As a consequence, we assume that if the mature generation has increased its stock of human capital, then the next cohort of young agents is endowed with a higher initial stock than the previous one. Of course, if there has been no learning, nothing can be transmitted. As a simplifying assumption, it is assumed that all the new knowledge and skills of the mature is entirely transmitted to the young, ${ }^{4}$ so that:

$$
h_{t+1}^{y}=h_{t+1}^{m}=h_{t}^{y} \mu\left(e_{t}\right),
$$

while each young agent of the first generation is endowed with one unit of human capital, i.e., $h_{0}^{y}=1$.

A young agent in period $t$ maximizes (1) subject to the budget constraints:

$$
w_{t} h_{t}^{y}=c_{t}^{y}+s_{t+1}+e_{t},
$$

and,

$$
w_{t+1} h_{t+1}^{m}+r_{t+1} s_{t+1}=c_{t+1}^{m},
$$

given the technologies (2) and (4) and the competitive prices (3). The equilibrium condition equating savings to investment is:

$$
k_{t+1}=s_{t+1} /\left(h_{t+1}^{m}+h_{t+1}^{y}\right)=s_{t+1} /\left(2 h_{t+1}^{m}\right) .
$$

The first order conditions (with respect to $s_{t+1}$ and $e_{t}$ ) associated with a non-corner optimal solution are:

$$
u^{\prime}\left(c_{t}^{y}\right)=r_{t+1} u^{\prime}\left(c_{t+1}^{m}\right),
$$

and,

$$
u^{\prime}\left(c_{t}^{y}\right)=w_{t+1} h_{t}^{y} \mu^{\prime}\left(e_{t}\right) u^{\prime}\left(c_{t+1}^{m}\right) .
$$

Consequently, for a non-corner solution, it must be that:

$$
h_{t}^{y} \mu^{\prime}\left(e_{t}\right)=r_{t+1} / w_{t+1}=[\alpha /(1-\alpha)] k_{t+1}^{-1} .
$$

\footnotetext{
${ }^{4}$ The same qualitative results hold when human capital of the young is simply proportional to that of the old.
} 
Because $\mu$ is increasing and concave and $\mu^{\prime}(0)=\gamma$, condition (7) implies that agents investing in both types of capital will invest at least the quantity:

$$
\bar{k}=[\alpha /(1-\alpha) \gamma],
$$

in physical capital. This has important consequences for the economy, which have been exploited for instance in Galor and Moav (2000).

Consider an economy with a relatively low level of per capita capital stock $k_{t}$. While the rate of return to investment in physical capital, $r_{t+1}$, is relatively large, the rate of return to investments in human capital, $w_{t+1} h_{t}^{y} \mu^{\prime}\left(e_{t}\right)$ given by equation (6), is relatively low, since $\mu^{\prime}(e)$ at most equals $\gamma$ because $\mu$ is increasing and concave and $\mu^{\prime}(0)=\gamma$. It is therefore optimal for agents to make no investments in human capital and to only invest in physical capital. This continues as long as agents invest less than the threshold $\bar{k}$, and implies that economies with relatively low per capita capital stock undergo a growth regime fueled exclusively by physical capital accumulation. In this neoclassical growth regime, the aggregate capital stock increases monotonically over time, while the aggregate human capital stock remains unchanged.

As a result, during the neoclassical growth regime, the rate of return to physical capital investment $r_{t+1}$ decreases over time, while the schedule for the rate of return on human capital investment, $w_{t+1} h_{t}^{y} \mu^{\prime}\left(e_{t}\right)$, keeps shifting up because of the increase in $w_{t+1}$. This implies the existence of a threshold, which is denoted $\bar{k}$, at which agents start investing jointly in human and physical capital. At this threshold, the economy enters a modern growth regime fueled by the combination of physical and human capital accumulation.

\subsection{The Two Growth Regimes}

\subsubsection{The Neoclassical Growth}

Consider an economy in period $t$ with a relatively low per capita capital stock, $k_{t}$, such that the rate of return to investment in physical capital is greater than the rate of return to investment in human capital, and $e_{t}=0$ (and has been so in the past). This implies that no investments in human capital are, or have been, made, so that $h_{t+1}^{y}=h_{t+1}^{m}=h_{t}^{y}=h_{0}^{y}=1$.

Substituting the equilibrium condition $k_{t+1}=s_{t+1} / 2$ and the competitive prices (3) in the first-order condition (5) gives:

$$
u^{\prime}\left(A(1-\alpha) k_{t}^{\alpha}-2 k_{t+1}\right)=A \alpha k_{t+1}^{\alpha-1} u^{\prime}\left(A(1-\alpha) k_{t+1}^{\alpha}+2 A \alpha k_{t+1}^{\alpha}\right) .
$$

With strictly concave utility $u$, (8) has a unique solution $k_{t+1}^{*}$, easily shown to be increasing in $k_{t}$. Since there is no change in human capital, growth in this regime is fueled exclusively by physical capital accumulation.

To better illustrate this result, consider the period utility $u(c)=\ln (c)$. Assuming a small per capita capital stock in period $t,{ }^{5}$ agents make no investment

\footnotetext{
${ }^{5}$ As discussed below, small here means that:

$$
k_{t}<(\bar{k} / B)^{1 / \alpha}
$$
}


in human capital, and the interior solution for savings satisfies the first order condition:

$$
1 / c_{t}^{y}=r_{t+1} / c_{t+1}^{m},
$$

which, substituted in the lifetime budget constraint of the agent, implies that:

$$
c_{t}^{y}=.5\left(w_{t} h_{0}^{y}+w_{t+1} h_{0}^{y} / r_{t+1}\right),
$$

or, equivalently, that:

$$
s_{t+1}=.5 h_{0}^{y}\left(w_{t}-w_{t+1} / r_{t+1}\right) .
$$

Combining this equation with the equilibrium condition and the competitive prices (3) generates the equilibrium law of motion of the per capita capital stock:

$$
k_{t+1}=B k_{t}^{\alpha},
$$

where $B=A[(1-\alpha) /(3+1 / \alpha)]$. Along the path described by this law of motion, growth is fueled solely by physical capital accumulation, and the per capita capital stock converges to a unique steady-state $k^{*}$ satisfying:

$$
k^{*}=B^{1 /(1-\alpha)},
$$

while human capital levels are constant and equal to $h_{0}^{y}$.

Given the law of motion for the per capita capital stock in the neoclassical regime in equation (9), agents will make no investments in human capital as long as $k_{t+1}<\bar{k}=[\alpha /(1-\alpha) \gamma]$, that is, as long as:

$$
k_{t}<(\bar{k} / B)^{1 / \alpha} .
$$

Figure 1 illustrates the case of an economy forever locked in the neoclassical regime, since the steady-state $k^{*}$ is smaller than the threshold $\bar{k}$ in Figure 1(a). As a consequence, aggregate human capital is constant over time, as shown in Figure 1(b).

\subsubsection{Modern Growth}

Suppose there exists a period $\bar{t}$ in which, for the first time, the per-capita capital stock $k$ reaches the threshold above which agents start investing in human capital. That is:

$$
k_{\bar{t}-1} \leq(\bar{k} / B)^{1 / \alpha} \text { and } k_{\bar{t}}>(\bar{k} / B)^{1 / \alpha} .
$$

where $B=A[(1-\alpha) /(3+1 / \alpha)]$. 
As a consequence, the first-order conditions associated with the period $\bar{t}$ decision problem form a system of two non-linear equations in the two unknowns $\left(c_{\bar{t}}^{y}, e_{\bar{t}}\right)$ which can be written as:

$$
u^{\prime}\left(c_{\bar{t}}^{y}\right)=r_{\bar{t}+1} u^{\prime}\left(w_{\bar{t}} h \frac{y}{t} r_{\bar{t}+1}+w_{\bar{t}+1} h \frac{y}{\bar{t}} \mu\left(e_{\bar{t}}\right)-r_{\bar{t}+1} c_{\bar{t}}^{y}-r_{\bar{t}+1} e_{\bar{t}}\right)
$$

and,

$$
\left.k_{\bar{t}+1}^{-1}=[(1-\alpha) / \alpha] h_{\frac{y}{t}}^{y}{ }^{\prime}\left(e_{\bar{t}}\right)=\left[h_{\bar{t}}^{y} 2 \mu\left(e_{\bar{t}}\right)\right)\right] /\left(w_{\bar{t}} h_{\bar{t}}^{y}-c_{\bar{t}}^{y}-e_{\bar{t}}\right) .
$$

The competitive prices $w_{\bar{t}+1}$ and $r_{\bar{t}+1}$ can be calculated from (3) and $h_{\bar{t}}^{y}=h_{0}^{y}$.

To illustrate the dynamics in this regime, consider the period utility $u(c)=$ $\ln c$ and the simple human capital accumulation technology $\mu\left(e_{\bar{t}}\right)=\left(1+\gamma e_{\bar{t}}\right)$. When $k_{\bar{t}}$ is above the threshold $(\bar{k} / B)^{1 / \alpha}$, young agents in period $\bar{t}$ make a strictly positive investment in $e_{\bar{t}}$ in human capital, and set their investment in physical capital such that:

$$
[(1-\alpha) / \alpha] h_{\bar{t}}^{y} \gamma=k_{\bar{t}+1}^{-1},
$$

since agents equate the return on physical capital investments to that of human capital investments. It addition, with $e_{\bar{t}}>0$, the human capital of the cohort of agents born in period $\bar{t}+1$ is strictly greater than that of the previous young generation since $h_{\bar{t}+1}^{y}=h_{\bar{t}}^{y}\left(1+\gamma e_{\bar{t}}\right)>h_{\frac{y}{t}}^{y}$. In all successive periods, young agents continue to equate the returns on both types of capital, so that, for all $t \geq \bar{t}:$

$$
[(1-\alpha) / \alpha] h_{t}^{y} \gamma=k_{t+1}^{-1} .
$$

As a consequence, after the threshold period $\bar{t}, h$ increases over time while $k$ decreases, which implies that the marginal product of capital, $w$, increases over time.

It can also be shown that, for all $t \geq \bar{t}$ :

$$
e_{t}=\left[(1-\alpha) w_{t} h_{t}^{y}-(1+3 \alpha) / \gamma\right] /[2+2 \alpha],
$$

so that investments in human capital increase over time since $w_{t} h_{t}^{y}$ rises. Notice that total savings in period $t$ is $N s_{t+1}$, which is equal to $N k_{t+1} h_{t}^{y}\left(1+\gamma e_{t}\right)$ and therefore proportional to $\left(1+\gamma e_{t}\right)$. This implies that aggregate savings, in addition to aggregate human capital, increase over time, and proves that growth in the modern regime is fueled by the joint accumulation of both physical and human capital.

In figure 2 , the change of regime takes place in period $\bar{t}$ when $k_{\bar{t}}$ in the neoclassical economy reaches the threshold $(\bar{k} / B)^{1 / \alpha}$ in figure $2(\mathrm{a})$. After that period, both aggregate human and physical capital increase over time, as depicted in figure 2(b). 


\section{$3 \quad$ Longevity and Growth}

\subsection{Health and Longevity}

This section of the paper introduces individual health capital as a new variable endogenously determined in the model. Health capital, denoted $b$ in the model, has several important characteristics. First, better health is more enjoyable; as a consequence, utility is assumed to be increasing in health capital. Second, better health leads to higher life expectancy, and therefore increases the demand for consumption goods. ${ }^{6}$ A slight modification of the model developed in the previous section permits accommodating these two features by defining the period utility function over the consumption good $c$ and the stock of health, denoted $b$, so that the preferences of an agent are represented by the utility function:

$$
u\left(c_{t}^{y}, b_{t}^{y}\right)+u\left(c_{t+1}^{m}, b_{t+1}^{m}\right),
$$

where $u$ is $C^{2}$, strictly increasing, $u_{11}<0, u_{22}<0$, and $u_{12} \geq 0$. This last condition simply imposes that health capital and consumption are weak complements.

Young agents have the opportunity to raise their health stock during maturity by investing some of their first period resources. Specifically, an agent's stock of health is assumed to evolve according to the following technology:

$$
b_{t+1}^{m}=b_{t}^{y} Z\left(m_{t}\right),
$$

where $m$ are the resources invested in health accumulation during the first period of the agent's life. The function $Z$ is $C^{2}$, strictly increasing and concave. In addition, it is assumed that in the absence of health investments the health stock is unchanged (i.e., $Z(0)=1$ ) and that marginal investments yield finite returns (i.e., $Z^{\prime}(0)=\delta<\infty$ ). Without loss of generality $b_{t}^{y}$ is normalized to one. ${ }^{7}$

The budget constraint of a young agent is:

$$
w_{t} h_{t}^{y}=c_{t}^{y}+e_{t}+s_{t+1}+m_{t},
$$

and the first-order condition associated with a strictly positive choice of health expenditures $m_{t}$ is:

$$
u_{1}\left(c_{t}^{y}, 1\right)=u_{2}\left(c_{t+1}^{m}, b_{t+1}^{m}\right) Z^{\prime}\left(m_{t}\right),
$$

while the other first order conditions are unchanged. Substituting the budget constraint in the previous equation gives:

$$
u_{1}\left(w_{t} h_{t}^{y}-e_{t}-s_{t+1}-m_{t}, 1\right)=u_{2}\left(s_{t+1} r_{t+1}+w_{t+1} h_{t+1}^{m}, Z\left(m_{t}\right)\right) Z^{\prime}\left(m_{t}\right) .
$$

\footnotetext{
${ }^{6}$ This paper ignores the positive contribution of a "good health" to labor productivity.

${ }^{7}$ Each generation thus starts with the same health capital, although the model can be amended to allow for some health spillover from one generation to the next.
} 
For given values of $e$ and $s$, the left-hand side is strictly increasing in $m$ (given the assumption that $u_{11}<0$ ), while the right-hand side decreasing in $m$ (given the assumption that $u_{22}<0$ and $Z$ concave), so that, generally, a simple condition can be derived under which there exists a unique solution. This condition is equivalent to that of the agent's income or consumption being above a particular threshold level, as illustrated by the following example. Consider the period utility:

$$
u(c, b)=\ln \left(c^{\theta} b^{1-\theta}\right)=\theta \ln c+(1-\theta) \ln b \text { where } 0<\theta<1,
$$

and the simple health production technology:

$$
b_{t+1}^{m}=\left(1+\delta m_{t}\right)^{\varepsilon},
$$

in which $(\delta, \varepsilon)$ are productivity parameters, and $0<\varepsilon \leq 1$. In this case, the first-order condition with respect to the choice of health expenditures is:

$$
\theta / c_{t}^{y}=(1-\theta) \delta \varepsilon /\left(1+\delta m_{t}\right),
$$

which has a strictly positive solution if and only if the first period consumption of the young agent $c_{t}^{y}$ is above the threshold level $c_{\min }=\theta /[(1-\theta) \delta \varepsilon]$, in which case agents invest the quantity:

$$
m_{t}=[(1-\theta) \varepsilon / \theta] c_{t}^{y}-1 / \delta
$$

in health. Note that the first period consumption threshold $c_{\min }$ depends negatively on $\delta \varepsilon$.

Recall that prior to agents starting to invest in health, an economy is either in one of the two regimes discussed in the previous section of the paper. Under both regimes consumption rises monotonically over time, and the term "Epidemiological Transition" denotes the first period during which consumption rises above the threshold level $c_{\min }$. Above this critical consumption level, agents begin investing in health and longevity increases. ${ }^{8}$ As discussed in the introduction, the Epidemiological Transition is a critical feature of the relationship between economic growth and the health and life expectancy of an economy's population that has been very well documented in the epidemiological and medical literature. The rest of this section demonstrates how the model can be used to understand the observed differences in the pattern of this transition in various countries.

\subsection{The Epidemiological Transition}

It is important to note that the relationship between economic growth and health and longevity runs both ways. Economic growth, and the associated rise in income and consumption levels, can affect the health status of a population by inducing an Epidemiological Transition after which health increases

\footnotetext{
${ }^{8}$ The findings in Fogel (1997) support the hypothesis that the early decrease in mortality was closely associated with improved consumption and nutrition.
} 
monotonically over time. Reciprocally, investments in health can affect economic growth through the combination of the following two channels. First, investing in health requires foregoing some amount of consumption and physical and human capital expenditures: It is therefore analogous to a negative wealth effect. Second, investing in health results in longer life expectancy, and thus leads to a shift of the demand for consumption in the second period, which in turn alters the agent's incentives to substitute away from consumption in the first period and toward accumulating capital, thus affecting growth in a positive manner. How these two effects combine depends of course on the choice of primitives for utility and production functions in the model.

Transition During the Neoclassical Growth Regime. Suppose first that the transition takes place during the neoclassical growth regime, which happens if and only if consumption during that regime attains the threshold level $c_{\text {min }}$ defined in the previous section. Agents then invest in health according to (10), and with constant human capital levels (normalized to 1), the lifetime budget constraint becomes:

$$
(1-\varepsilon+\varepsilon / \theta) c_{t}^{y}+c_{t+1}^{m} / r_{t+1}=1 / \delta+w_{t}+w_{t+1} / r_{t+1} .
$$

Combining this with the first order condition (5) associated with optimal savings gives:

$$
c_{t}^{y}=(2-\varepsilon+\varepsilon / \theta)^{-1}\left(1 / \delta+w_{t}+w_{t+1} / r_{t+1}\right),
$$

or, equivalently:

$$
s_{t+1}=(2-\varepsilon+\varepsilon / \theta)^{-1}\left[w_{t}+1 / \delta-(1-\varepsilon+\varepsilon / \theta)\left(w_{t+1} / r_{t+1}\right)\right] .
$$

Substituting the competitive prices and the equilibrium condition $k_{t+1}=s_{t+1} / 2$ in the last equation generates a law of motion for per-capita capital stock post the epidemiological transition given by:

$$
k_{t+1}=\left[1 / \delta+A(1-\alpha) k_{t}^{\alpha}\right] /[3+1 / \alpha+\varepsilon(-1+1 / \theta)(1+\alpha) / \alpha]=B^{\prime} k_{t}^{\alpha}
$$

At the time consumption in the neoclassical regime reaches the threshold $c_{\min }$, agents start investing in health and the law of motion for the per-capita capital stock thus changes from (9) to (11). As a result, the economy converges to a new steady-state, which can be shown to be higher if $B^{\prime} \geq B$, that is, if:

$$
k^{*}<\alpha \theta /[\delta(1+\alpha) \varepsilon(1-\theta)] .
$$

If that condition is satisfied, since the economy engages on a higher growth path, there is an immediate increase in the rate of growth of per capita income, as shown in Figure 3 In Figure 3(b), the consumption threshold $c_{\min }$ is reached in period $\widetilde{t}$, at which the economy switches to a higher growth path in Figure $3(\mathrm{a})$.

It is important to note that, because the epidemiological transition generates an immediate jump in per-capita capita stock and puts the economy on a higher 
growth path, it may facilitate the transition from a neoclassical to a modern regime, because the threshold $\bar{k}$ may be more rapidly reached during the higher growth path. Further, the epidemiological transition may help an economy reach a modern growth regime that it would not have otherwise entered. The model in this paper thus leads to the important hypothesis that health is a very critical determinant of long term economic growth because it can accelerate or even induce the switch from a neoclassical to a modern growth regime. ${ }^{9}$

Transition During the Modern Regime. Alternatively, suppose that the epidemiological transition takes place during the modern growth regime. With strictly positive investments in health, the lifetime budget constraint becomes:

$$
(1-\varepsilon+\varepsilon / \theta) c_{t}^{y}+c_{t+1}^{m} / r_{t+1}+e_{t}=1 / \delta+w_{t} h_{t}^{y}+w_{t+1} h_{t+1}^{m} / r_{t+1} .
$$

Substituting the first-order conditions with respect to savings and investments in human capital (5) and (6) in the previous equation leads to:

$$
c_{t}^{y}=\left(1 / \delta+w_{t} h_{t}^{y}+1 / \gamma\right) /(2-\varepsilon+\varepsilon / \theta) .
$$

Using this expression in the equilibrium condition:

$$
k_{t+1}^{-1}=h_{t}^{y} 2\left(1+\gamma e_{t}\right) /\left[w_{t} h_{t}^{y}+1 / \delta-(1-\varepsilon+\varepsilon / \theta) c_{t}^{y}-e_{t}\right],
$$

and, given that:

$$
k_{t+1}^{-1}=[(1-\alpha) / \alpha] h_{t}^{y} \gamma,
$$

the optimal solution for $e$ is:

$$
e=[1 /(1+\alpha)]\left[\left(w_{t} h_{t}^{y}+1 / \delta-\Delta\right)(1-\alpha)-2 \alpha / \gamma\right],
$$

where $\Delta=1-1 /(2-\varepsilon+\varepsilon / \theta)$.

As a consequence, the per capita human capital level rises over time. The economy combines a modern growth regime with strictly positive investments in health generating increases in agents' longevity. In Figure 4(a) the transition to the modern growth regime occurs at $\bar{t}$, and is followed by the Epidemiological Transition at $\widetilde{t}$.

Exogenous Transition. Finally, there is also the possibility that the economy does not reach the epidemiological transition endogenously through the growth process, but that this transition is initiated by external factors such as changes in health technology affecting the health parameters. Recall that an increase in either $\delta$ or $\varepsilon$ leads to a lowering of the threshold consumption level $c_{\min }$ at which agents start investing in health. In Figure $4(\mathrm{~b})$, the lowering of the threshold $c_{\text {min }}$ below the steady-state consumption $c^{*}$ of the neoclassical regime enables an economy to switch to a modern growth regime at $\bar{t}$. Without the exogenous change in health technology, the switch may not have been otherwise possible (unless $c^{*}<c_{\min }$ ), and the economy would have been locked into a regime of relatively low income, low education, and low health. ${ }^{10}$

\footnotetext{
${ }^{9}$ Other researchers have also argued that a mortality decline can foster the transition to a modern growth regime, although other mechanisms were considered (see, for instance, Kalemli-Ozcan, 2000).

${ }^{10}$ A poverty trap similar to that in Galor and Mayer-Foulkes (2002).
} 
Figure 4(b) thus demonstrates that changes in the availability of health and in the productivity and costs of the health sector can have important dramatic consequences for the long term development of an economy. It also suggests that fostering growth through policies aimed at increasing the rate of return on education may be best achieved in combination with health policies.

\subsection{The Theory of the Epidemiological Transition}

The analysis and comparison of mortality patterns in several economies has led Omran $(1971,1982)$ to formulate his "Theory of the Epidemiological Transition." This theory starts with the premise that mortality is a fundamental factor in population dynamics (Proposition 1) and with the observations that the epidemiological transition represents a long term shift in mortality from a regime of mostly infectious diseases to a regime of mostly degenerative and man-made diseases (Proposition 2). The epidemiological transition is shown to favor the young over the old and females over males (Proposition 3 ) and to be closely associated with rising standards of living and improved nutrition in the 19th Century, and improved medical and health practices in the 20th Century (Proposition 4).

The most interesting feature of the Theory of the Epidemiological Transition is that three ${ }^{11}$ basic patterns of the transition emerge (Proposition 5): The classical or Western model, the accelerated model, and the delayed model. These three patterns are shown to fit very well the three scenarios of an endogenous transition during the neoclassical regime, an endogenous transition during the modern regime, or a transition triggered by exogenous factors.

The Classical Model of Epidemiological Transition (England, most Western European countries). The mortality pattern follows three stages. A pre-industrial age of pestilence and famine generates a cyclical population growth with frequent peaks in mortality is followed by an intermediate stage of recceeding pandemics in the middle or later part of the 19th Century giving way to a gradual mortality decline. A stage of degenerative and man made diseases in the 20th Century corresponds to more precipitous declines. Economic factors (improvements in standards of living and in nutrition in the 19th Century) were the primary determinants of the classical transition, but were later augmented in the 20th Century by sanitary improvements, followed by medical and public health progress. The Epidemiological Transition closely parallels the demographic transition and Industrial Revolution and is therefore followed by a population explosion and by sustained economic growth. In the model of this paper, the classical transition corresponds to the endogenous epidemiological transition during the neoclassical growth regime (See Figure 3).

The Accelerated Model (Japan). The transition follows a similar patter as the Classical Model, but the changes in mortality occurred at a later stage of development and were more rapid. This corresponds to the endogenous transition taking place during the modern growth regime, as depicted in Figure

\footnotetext{
${ }^{11}$ Four when counting the transitional variant of the delayed model.
} 
4(a).

The Delayed Epidemiological Transition (most countries in Africa, Latin America, and Asia). The substantial decreases in mortality in these economies are very recent. Public health measures have been a major component of a generally imported medical package that pulled mortality down while keeping fertility high, thus generating a population explosion. This pattern corresponds to a transition triggered by changes in the exogenous parameters characterizing the health technology, as shown in Figure 4(b).

\section{Conclusion}

It is clear that economic growth has a direct impact on the health and longevity of a population through increasing levels of income, consumption and health investments. In addition to this obvious link, a reverse mechanism through which the health status of a population, closely associated with longevity or life expectancy, affects economic growth cannot be ignored: Increased longevity induces agents to spend more on capital investments, which in turn affects economic growth. Combining the channels to and from growth, this paper presents a model of the long term interaction between economic growth and longevity showing that health (longevity) increases with income, but only above a specific threshold level, at which an economy undergoes an "Epidemiological Transition", and predicts three patterns for this transition. These three patterns are consistent with the empirical literature under the name of the "Theory of the Epidemiological Transition".

In addition, this paper derives the important hypothesis that a health transition can help a country switch from a neoclassical growth regime to a modern growth regime. The paper also suggests that health policies in developing countries can have important consequences for long term growth, and not only for the immediate well-being of the population, and that inducing economic growth through policies aimed at increasing the rate of return on education may be best achieved in combination with health policies.

\section{REFERENCES}

Acsadi, G. and J. Nemeskeri (1970) History of Human Life Span and Mortality, Akademiai Kiado, Budapest.

Bloom, D.E. and D. Canning (2000) "The Health and Wealth of Nations" Science, vol.287, February 182000.

Fogel, R. (1997) "New Findings on Secular Trends in Nutrition and Mortality: Some Implications for Population Theory." in Mark Rosenzweig and Oded Stark, eds. The Handbook of Population and Family Economics Volume 1A Amsterdam: North Holland, 1997.

Galor, O. and D. Mayer-Foulkes (2002) "Food for Thought: Basic Needs and Persistent Educational Inequality" mimeo. 
Galor, O. and O. Moav (2000) "Das Human Kapital" mimeo, Brown University.

Galor, O. and D. Weil (2000) "Population, Technology, and Growth: From the Malthusian Regime to the Demographic Transition" American Economic Review 90, 806-828.

Galor, O. and D. Weil (1999) "From Malthusian Stagnation to Modern Growth" American Economic Review 89, 150-154.

Grossman, M. (1972) The Demand for Health: A Theoretical and Empirical Investigation. New York: Columbia University Press.

Haines, M. (1995) "Disease and Health through the Ages" pp.51-60 in The State of Humanity (Julian L. Simon, ed.) Blackwell Publisher Inc.

Hassan, F. A. (1981) Demographic Archaeology, Academic Press, Inc.

Kalemli-Ozcan, Sebnem (2002) Does the Mortality Decline Promote Economic Growth? Mimeo, University of Houston.

Kremer, M. (1993) "Population Growth and Technological Change: One Million B.C to 1990" Quarterly Journal of Economics 108, 681-716.

Lucas, R. (1988) "On the Mechanics of Economic Development" Journal of Monetary Economics 22, 3-42.

Mirman, L.J. (1971) "Uncertainty and Optimal Consumption Decisions" Econometrica, 39(1), pp.140-146.

Morand, O.F. (2001) "Evolution through Revolutions: Growing Population and Changes in Modes of Production" mimeo, University of Connecticut.

Omran, A.R. (1971) "The Epidemiologic Transition" Milbank Memorial Fund Quarterly 49(1), pp.509-538.

Omran, A.R. (1982) "Epidemiologic Transition" in International Encyclopedia of Population, Volume 1. (John A. Ross, ed.) The Free Press.

Van Zon, A. and J. Muysken (2001) "Health and Endogenous Growth" Journal of Health Economics, 20, 169-185. 
1(a)

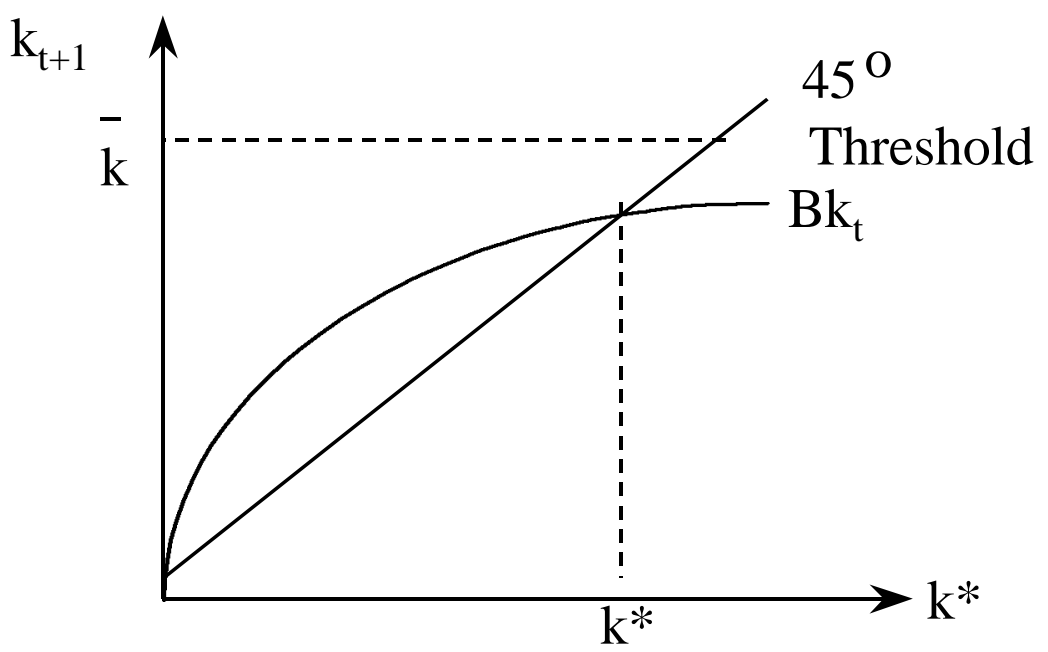

\section{Fig. 1 NEOCLASSICAL GROWTH REGIME}

$1(b)$

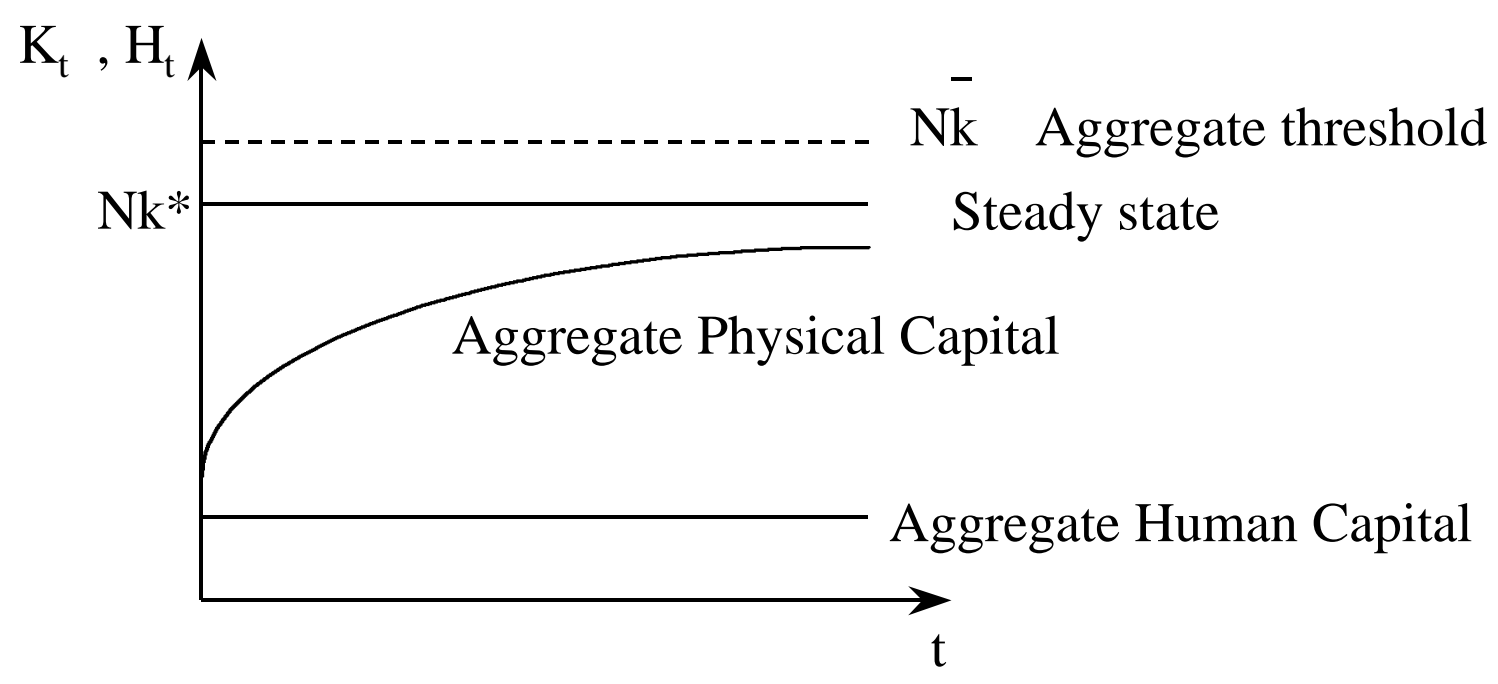


2(a)

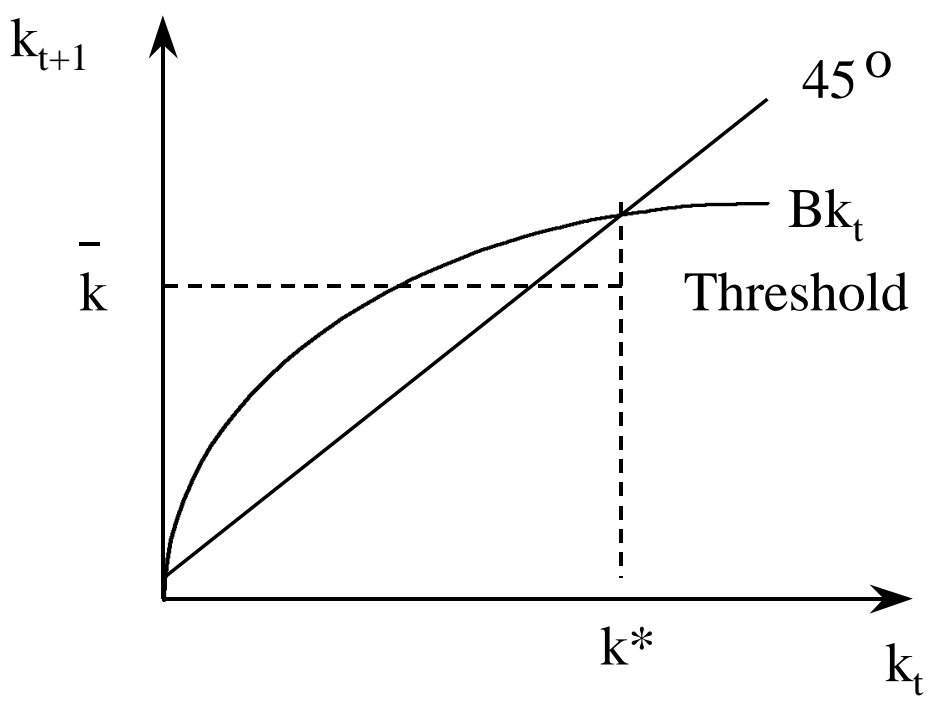

\section{Fig.2 MODERN REGIME}

2(b)

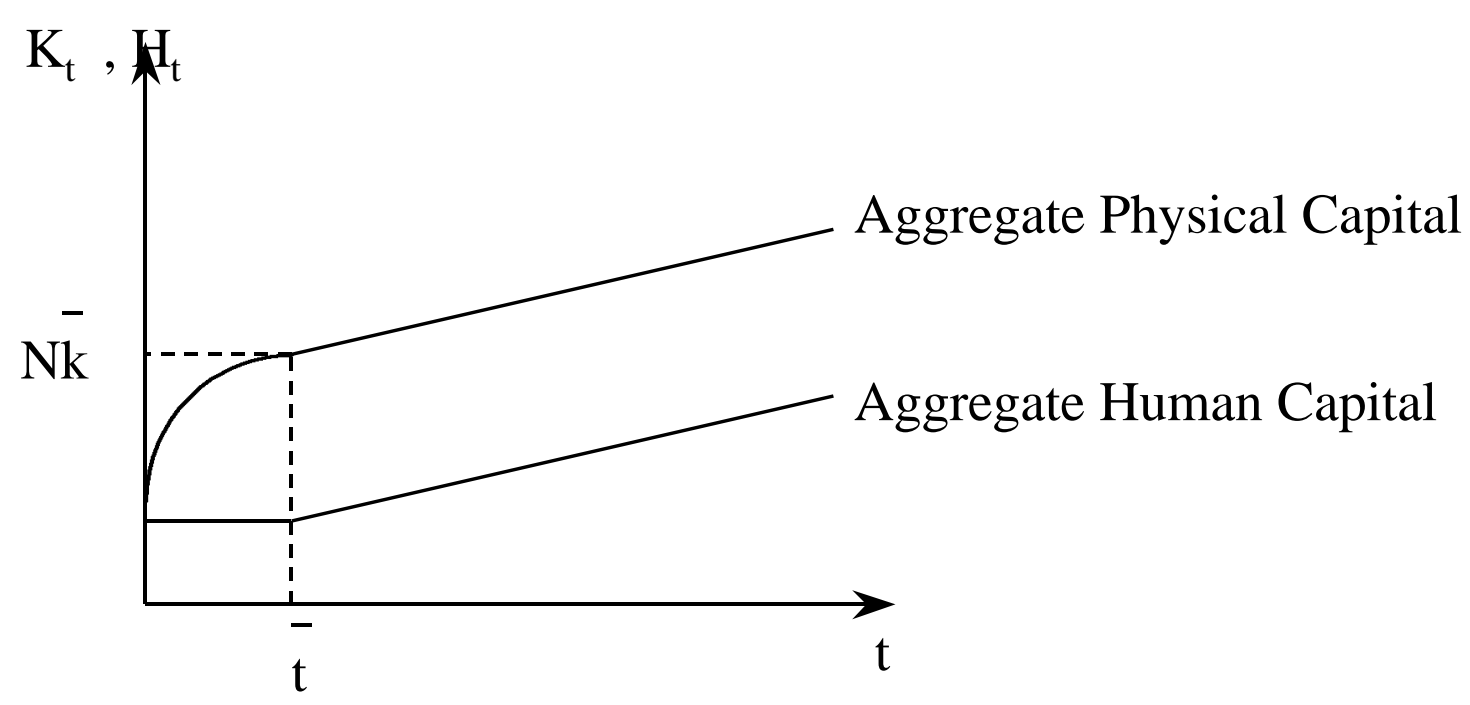


3(a)

3(b)

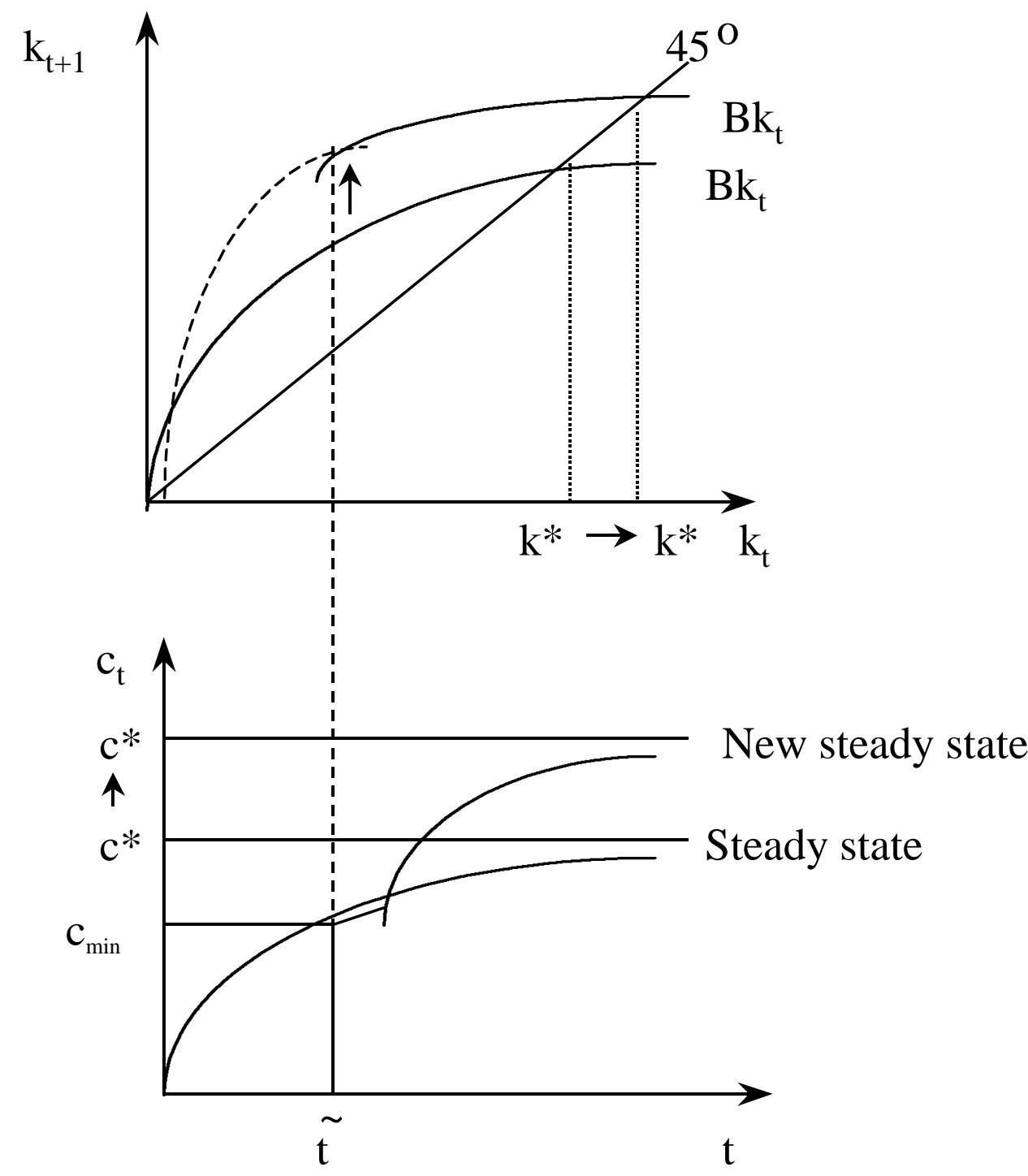

Fig. 3 ENDOGENOUS TRANSITION DURING THE NEOCLASSICAL REGIME 
4(a)

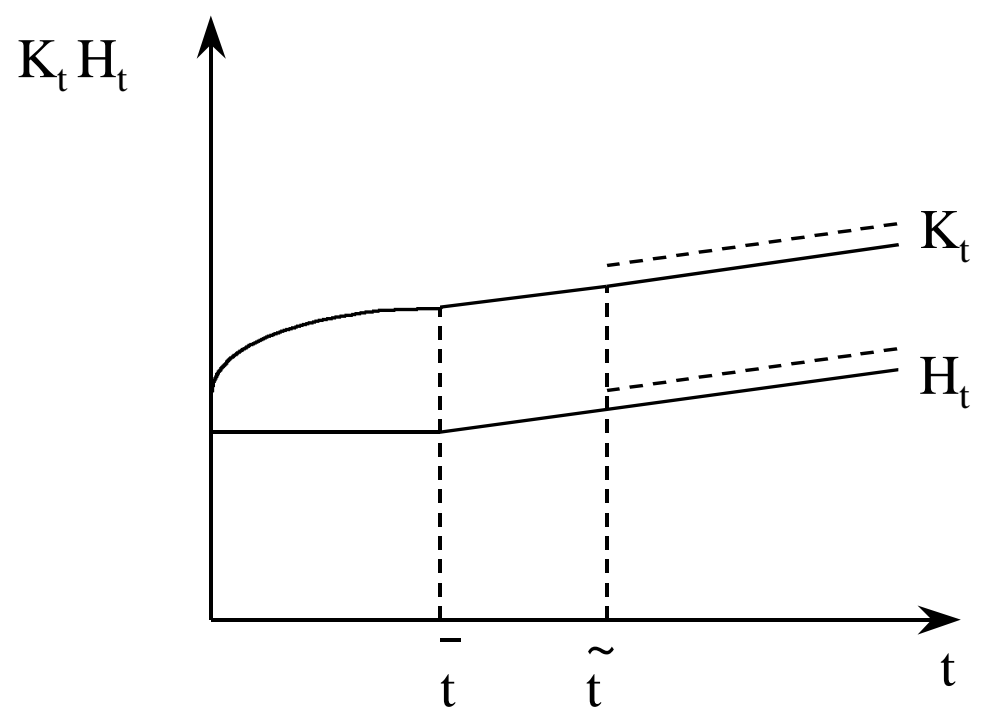

ENDOGENOUS TRANSITION DURING THE MODERN REGIME

4(b)

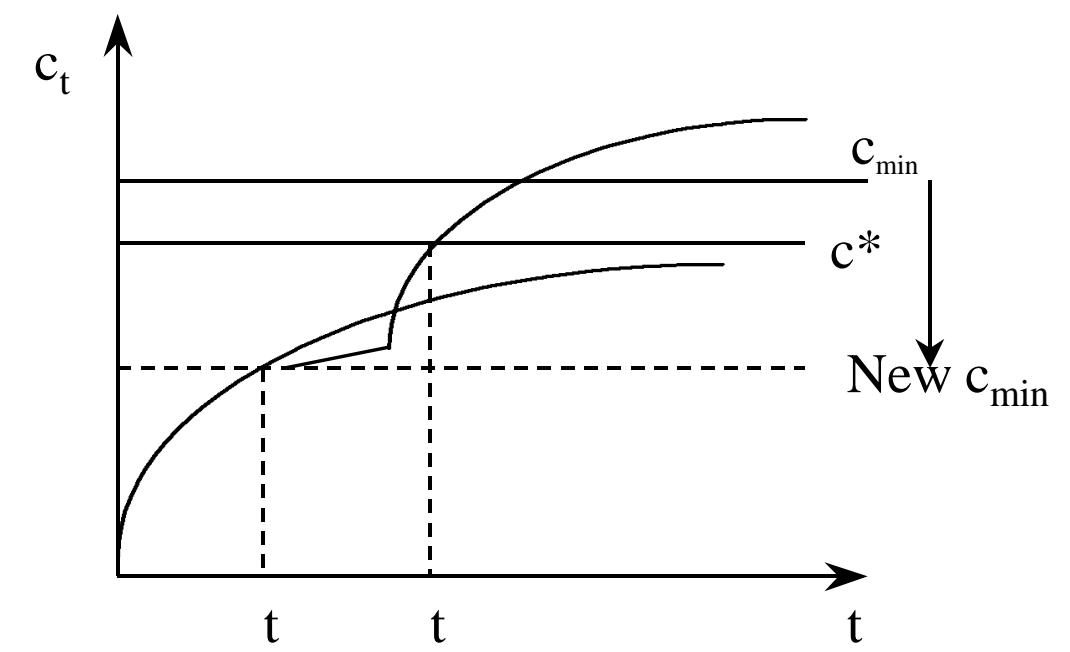

ENDOGENOUS TRANSITION DUE TO CHANGES IN HEALTH TECHNOLOGY 